\title{
REFLECTIONS ABOUT THE CREATIVE PROCESS OF THE ARCHITECTURAL PROJECT AND ITS TEACHING
}

\author{
Alba Dorado, María Isabel \\ Departamento de Arte y Arquitectura \\ Universidad de Málaga, SPAIN. Campus de Excelencia Internacional Andalucía Tech \\ maribelalba@uma.es
}

\begin{abstract}
This paper aims to reflect on the importance of the eye in the creative process of architectural projects. All creation is based on a watchful eye, which acts as an instrument of knowledge and reflection; an active and creative eye that contains a thought. But creation is also in the hands of those who put these thoughts down onto paper and materialise them.

In this sense, teaching architectural design should fundamentally consider educating the eye, so that students develop a perceptual ability allowing them to address all kinds of architectural projects creatively.

Educating the eye therefore becomes the main goal of teaching architectural design. Learning how to see is essential. This learning calls on the eye as an instrument of knowledge and analysis of the reality to be transformed. An eye with a purpose not just of looking at something for the sake of it, but of seeing it, of seeing it to learn and to become aware of the world surrounding us, whether physically, emotionally or intellectually. An eye that focusses on the reality around them in a conscious and attentive way in order to provide the information to work with when it comes to designing, both from an objective and rational outside world and an intimate and personal world. A creative eye, capable of creating and transforming reality. An eye that involves the action of thinking. But above all, an eye that acts in coordination with hands that work as instruments of knowledge, that move between the world of matter and thought, and that allow this world of ideas to be unearthed, spilling thoughts onto paper, specifying them and fixing them until turning them into something that can be built. In the teaching of architectural design, it would be necessary to foster this action as a way of doing and thinking.
\end{abstract}

Keywords: Learning, teaching, methodology, architecture, architectural project, eye. 